\title{
An observational study on safety and efficacy of povidone-iodine for pleurodesis in cancer patients
}

\author{
Ayush Makkar, Sanjeev Patni',Anjum Khan Joad', Kamal Kishor Lakhera
}

\begin{abstract}
Introduction: Pleurodesis is a time-honored procedure for malignant effusion as one of the palliative procedures to treat recurrent effusions.Various agents have been used in the past such as tetracycline, talc, bleomycin, and povidone-iodine. This paper aims at evaluating safety and efficacy of povidone-iodine for the procedure. Materials and Methods: One hundred and four patients underwent of pleurodesis with povidone-iodine done at our center for malignant effusion between June 2008 and August 20I5. The safety and efficacy of the procedure was analyzed. Results: One hundred and four patients of malignant effusion with mean age of 53 years and a mean follow-up of 7.8 months were evaluated.A total of $79 \%$ patients did not show any reaccumulation of fluid in their follow-up. There was no periprocedural mortality. Eight patients had severe pain; eleven patients had fever, while one patient had arrhythmia. Conclusion: Povidone-iodine is a simple, cheap, and effective method of pleurodesis with no major complication and a high success rate.

Key words: Malignant pleural effusion, pleurodesis, povidone-iodine
\end{abstract}

\section{Introduction}

Pleurodesis defined as symphysis between two layers of pleura to prevent recurrence of effusion. Chemical pleurodesis is the best available treatment for recurrent effusions of incurable malignancies. An ideal agent must be highly effective, easy to administer, safe, inexpensive, and readily available. Such an ideal agent is yet to be identified, and choice depends on the local availability and experience. Povidone-iodine is a topical antiseptic and has been shown to be safe and effective in several series ${ }^{[1-5]}$ including one multicenter study ${ }^{[3]}$ and in two small series. ${ }^{[5,6]}$ Povidone-iodine was selected over the other agents due to its cost-effectiveness and fewer side effects. This study aims to assess the safety and efficacy of povidone-iodine for pleurodesis.

\section{Materials and Methods}

This study was done to evaluate the efficacy of the pleurodesis procedure with povidone-iodine. One hundred and four cases of malignant pleural effusion that underwent pleurodesis with povidone-iodine for symptomatic effusion at our center from the period of June 2008 to August 2015 were analyzed. The British Thoracic Society guidelines were followed for managing malignant pleural effusion and for pleurodesis. ${ }^{[7]}$ Chest tube $(28 \mathrm{~F})$ was inserted through the midaxillary line in the fifth intercostal space to achieve complete drainage of the effusion and lung re-expansion. Re-expansion was verified radiographically. As soon as the effusion was completely drained and the lung fully expanded, pleurodesis was performed. Pleurodesis was done after a mean duration of 11.72 days (range 3-36 days) after the placement of intercostal drain. Lidocaine $(4 \mathrm{mg} / \mathrm{kg})$ diluted with normal saline to a volume of $50 \mathrm{ml}$ was infused through the chest tube. Implanted cardioverter defibrillator (ICD) was clamped for $15 \mathrm{~min}$, and patient was advised to change position for distribution of anesthetic agent uniformly. After $15 \mathrm{~min}$, a pleurodesis solution containing a mixture of $20 \mathrm{ml} 10 \%$ povidone-iodine and $80 \mathrm{ml}$ normal saline solution was infused into the pleural cavity, after which the tube was clamped for $2 \mathrm{~h}$, and patient

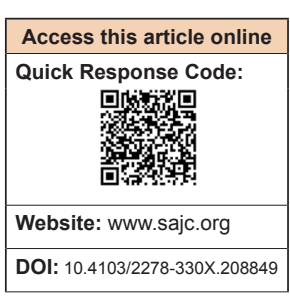

Departments of Surgical Oncology and 'Anaesthesia and Palliative Care, Bhagwan Mahaveer Cancer Hospital and Research Centre, Jaipur, Rajasthan, India

Correspondence to: Dr. Sanjeev Patni, E-mail: sanjeevnidhi@yahoo.com was again instructed to change position frequently. After $2 \mathrm{~h}$, the chest tube was unclamped. The intercostals drainage tube was removed as soon as the chest radiograph showed total lung re-expansion and no residual pleural effusion at a mean of 1.8 days (range $1-6$ days).

\section{Results}

Out of 104 cases, $65 \%$ of the cases were females and $35 \%$ were male. The mean age was 53 years (range 35-73 years). All the patients had recurrent pleural effusion associated with malignancy. Seventy-six (79\%) patients had successful pleurodesis showing no evidence of reaccumulation of fluid in pleural cavity during their follow-up. Twenty-eight patients $(26.9 \%)$ developed re-effusion on follow-up, after pleurodesis. Carcinoma lung and breast formed the major group accounting for $44.2 \%$ and $36.6 \%$, respectively. Carcinoma ovary was the cause in $9(8.6 \%)$ patients. Lymphoma, mesothelioma, and melanoma were the rare cause.

All patients had large amount of effusion $(>800 \mathrm{ml})$ that was allowed to drain gradually to prevent pulmonary edema, and pleurodesis was done after assuring complete drainage. Moderate pleural effusion (800-1500) seen in 78 (75\%) patients and gross effusion $(>1500)$ in $36(25 \%)$ patients.

There was no periprocedural mortality. Periprocedural pain was managed with oral nonsteroidal anti-inflammatory drug and tramadol. Eight patients $(7.7 \%)$ had excessive pain and required intravenous analgesia round the clock for 3-4 days. Eleven patients $(10.6 \%)$ also experienced high-grade fever that subsided in 2-3 days with antipyretics and oral antibiotics. Five patients $(4.8 \%)$ had ICD wound site infection and one had a transient arrhythmia.

The mean follow-up was 7.68 months (range 2-23 months), with $80(77 \%)$ patients died at their last follow-up.

\section{Discussion}

Chemical pleurodesis is the procedure of choice in the management of recurrent malignant pleural effusions. The best choice of sclerosing agent is still debatable. An ideal sclerosing

This is an open access article distributed under the terms of the Creative Commons Attribution-NonCommercial-ShareAlike 3.0 License, which allows others to remix, tweak, and build upon the work non-commercially, as long as the author is credited and the new creations are licensed under the identical terms.

For reprints contact: reprints@medknow.com

How to cite this article: Makkar A, Patni S, Joad AK, Lakhera KK. An observational study on safety and efficacy of povidone-iodine for pleurodesis in cancer patients. South Asian J Cancer 2017;6:79-80. 
agent should have a high molecular weight and chemical polarity, low regional clearance, rapid systemic clearance, and a steep dose-response curve and should be well tolerated with minimal or no side effects. ${ }^{[7]}$ The choice of a sclerosing agent is not only determined by the efficacy of the agent but also by its cost, accessibility, safety, ease of administration, and the number of administrations required to achieve a complete response.

Although talc is effective, there is an increasing concern about its safety. ${ }^{[8,9]}$ In a study by Walker-Renard et al., ${ }^{[10]}$ talc has been the most effective chemical agent for malignant pleural effusions, with a complete success rate of $93 \%$ in 1168 patients, compared with Corynebacterium parvum (76\%), tetracycline (67\%), doxycycline (72\%), and bleomycin (54\%).

The efficacy of povidone-iodine has been previously described. In a study by Echavarría et al., ${ }^{[1]}$ pleurodesis with povidone-iodine was performed in 15 patients with malignant pleural effusions and achieved control of the effusion in all the patients. In another study by Kelly-Garcia et al. ${ }^{[5]}$ success was achieved in 9 of 14 patients $(64.2 \%)$ in whom povidone-iodine pleurodesis was performed.

Povidone-iodine is iodine-based topical antiseptic. The mechanism of action of povidone-iodine appears to be related to enhanced sclerosis although the precise mode of action remains unclear. It may be related to the low $\mathrm{pH}$ (2.97) of the sclerosing solution. ${ }^{[4]}$ Furthermore, iodine has strong oxidative and cytotoxic properties, which can induce a potent inflammatory response in the wall of any fluid-containing structure. Moreover, povidone-iodine may have anti-exudative properties related to the chelation of proteins. ${ }^{[6]}$ Theoretically, the mechanism could also be similar to that described for talc, namely, the production of fibroblast growth factor. ${ }^{[8]}$

Although povidone-iodine does cause chest pain, intensity described in different studies varies as procedural sedation has been used in most studies. Another side effect reported was the occurrence of hypotension in three patients with mesothelioma. ${ }^{[6]}$ However, it was not clear whether the hypotension was an anaphylactic reaction or a pain-associated vasovagal reaction. However, iodine can cause severe allergic reactions, especially in patients with an allergic diathesis, and one should be prepared to deal with this emergency.

\section{Conclusion}

The efficacy of povidone-iodine is comparable to that of talc but without the risk of severe complications such as acute respiratory distress syndrome. Pleurodesis with povidone-iodine can be performed under local anesthesia with excellent tolerance. In conclusion, povidone-iodine is an effective, safe, readily available, and inexpensive agent for chemical pleurodesis in cases of recurrent, incapacitating effusions.

Financial support and sponsorship

Nil.

\section{Conflicts of interest}

There are no conflicts of interest.

\section{References}

1. Echavarría A, Pinzón V, Barés JP, Fernández E. Intracavitary treatment of malignant pleural effusion with iodine-povidone. Rev Med Panama 1991; 16:69-74.

2. Estrada Saló G, Farina Ríos C, Fibla Alfara JJ, Gómez Sebastián G, Unzueta MC, León González C. Spontaneous pneumothorax: Pleurodesis with an iodo-povidone hydroalcoholic solution. Arch Bronconeumol 2003;39: 171-4.

3. Olivares-Torres CA, Laniado-Laborín R, Chávez-García C, León-Gastelum C, Reyes-Escamilla A, Light RW. lodopovidone pleurodesis for recurrent pleural effusions. Chest 2002;122:581-3.

4. Brissaud O, Desfrere L, Mohsen R, Fayon M, Demarquez JL. Congenital idiopathic chylothorax in neonates: Chemical pleurodesis with povidone-iodine (Betadine). Arch Dis Child Fetal Neonatal Ed 2003;88:F531-3.

5. Kelly-Garcia J, Roman-Berumen JF, Ibarra-Perez C. Iodopovidone and bleomycin pleurodesis for effusions due to malignant epithelial neoplasms. Arch Med Res 1997;28:583-5.

6. Godazandeh G, Qasemi NH, Saghafi M, Mortazian M, Tayebi P. Pleurodesis with povidone-iodine, as an effective procedure in management of patients with malignant pleural effusion. J Thorac Dis 2013;5:141-4.

7. Antunes G, Neville E, Duffy J, Ali N; Pleural Diseases Group, Standards of Care Committee, British Thoracic Society. BTS guidelines for the management of malignant pleural effusions. Thorax 2003;58 Suppl 2:ii29-38.s.

8. Werebe EC, Pazetti R, Milanez de Campos JR, Fernandez PP, Capelozzi VL, Jatene FB, et al. Systemic distribution of talc after intrapleural administration in rats. Chest 1999;115:190-3.

9. Campos JR, Werebe EC, Vargas FS, Jatene FB, Light RW. Respiratory failure due to insufflated talc. Lancet 1997;349:251-2.

10. Walker-Renard PB, Vaughan LM, Sahn SA. Chemical pleurodesis for malignant pleural effusions. Ann Intern Med 1994; 120:56-64. 